\title{
Colonic dysfunction in acute diarrhoea: the role of luminal short chain fatty acids
}

\author{
B S Ramakrishna, V I Mathan
}

\begin{abstract}
Faecal concentrations and output of short chain fatty acids (SCFA) were assessed on successive days by gas-liquid chromatography in 24 patients with acute watery diarrhoea. Absorption of water and sodium from the rectum was also measured by a dialysis technique in 17 of these patients and in nine normal subjects in the presence and absence of luminal SCFA. Faecal SCFA concentrations were low on the first day of diarrhoea (mean (SEM) 9.9 (5.8) $\mathrm{mmol} / \mathrm{kg}$ ) and increased to 94.8 (16.4) $\mathrm{mmol} / \mathrm{kg}$ by the fifth day. Faecal output of SCFA corresponded to these figures. Net water absorption, in the absence of luminal SCFA, was stopped in patients with acute diarrhoea $\left(-59(81) \mathrm{nl} / \mathrm{cm}^{2} / \mathrm{min}\right)$ compared with healthy controls (+322 (63) $\left.\mathrm{nl} / \mathrm{cm}^{2} / \mathrm{min}\right)$ $(\mathbf{p}<0.01)$. Luminal SCFA restored net water absorption to $+184(67) \mathrm{nl} / \mathrm{cm}^{2} / \mathrm{min}$ in patients with acute diarrhoea $(p<0.01)$. Net absorption of sodium decreased in patients with acute diarrhoea in the absence of luminal SCFA, but returned to normal with luminal SCFA. Net secretion of potassium increased in acute diarrhoea, and did not change in the presence of SCFA. Defective absorption from the rectum in acute diarrhoea is reversed by luminal SCFA. The reduction of luminal SCFA in acute diarrhoea treated conventionally may be a factor contributing to colonic dysfunction.

(Gut 1993; 34: 1215-1218)
\end{abstract}

The normal absorptive capacity of the colon, estimated to be as much as six litres per day, should be able to compensate for significant fluid losses from the small intestine in secretory diarrhoea. While fluid secretion in human cholera is thought to occur predominantly from the small intestine, ${ }^{23}$ recent data ${ }^{4}$ suggest that water absorption from the colon is reduced or that the colon may even be in a net secretory state. It has also been shown that cholera toxin and heat stable enterotoxin of Escherichia coli can induce fluid secretion in the rat colon. ${ }^{5}$ Short chain fatty acids (SCFA), the main anions in the colon, ${ }^{6}$ and a potent stimulus for sodium absorption, ${ }^{7-9}$ can reverse toxin induced net water secretion in the rat colon. ${ }^{5}$ This suggests two possible mechanisms for the reported abnormalities of fluid absorption in the colon in cholera the direct effect of cholera toxin or a reduction in SCFA generation from unabsorbed dietary carbohydrates because of changes in the colon. This paper confirms abnormal fluid absorption in the colon in patients with acute watery diarrhoea including cholera, and shows that the concentration and output of SCFA in faeces in patients with acute watery diarrhoea is reduced, and that the addition of luminal SCFA can reverse the impairment of colonic absorption.

\section{Methods}

\section{SUBJECTS}

Patients with acute watery diarrhoea presenting to the hospital Emergency Service were admitted to a metabolic ward for the study. All the patients had diarrhoea of less than three days. None of them had been treated before admission to hospital, and none had any other medical disorders. Treatment for all these patients was standardised and consisted of correction of dehydration by the administration of World Health Organisation glucose oral rehydration solution supplemented by parenteral fluids where necessary. If tolerated, a normal diet was introduced after the second day. None of the patients received antibiotics. The study protocol was approved by the Ethics and Research Committees of the Christian Medical College and Hospital, Vellore.

Twenty four patients, 14 male and 10 female, presenting with watery diarrhoea clinically diagnosed as cholera in the Emergency Service, were included in the study. Their ages ranged from 18 to 65 years. Eleven of these patients were recruited for the study during the first 24 hours of illness. A diagnosis of cholera was confirmed in 15 patients on the basis of isolation of Vibrio cholerae from the stool.

FAECAL COLLECTION AND ANALYSIS FOR SCFA

Faeces were collected in plastic buckets to which $10 \mathrm{ml}$ of thiomersal solution (1:1000) had been added and immediately stored at $4^{\circ} \mathrm{C}$. The 24 hour collection was pooled daily, homogenised, and weighed and aliquots were stored at $-20^{\circ} \mathrm{C}$ until analysis. Where necessary, known amounts of distilled water were added to the faeces before homogenisation. SCFAs were extracted into ether from acidified aliquots of faeces ${ }^{10}$ after the addition of isovaleric acid ( $10 \mu \mathrm{mol}$ per $\mathrm{g}$ faeces) as an internal standard. The ether was evaporated under nitrogen after the addition of $4 \mathrm{M}$ $\mathrm{NaOH}$, and extracts stored at $-20^{\circ} \mathrm{C}$ until analysis. Before analysis, the extract was acidified with $4 \mathrm{M} \mathrm{H}_{2} \mathrm{SO}_{4}$ and dissolved in n-hexane. SCFAs were measured in the extract by gasliquid chromatography on a Pye Unicam PU 4550 chromatograph." One $\mu l$ of extract was injected into a column of $20 \%$ neopentenylglycolsuccinate on Gaschrom Q 80-100 mesh, and SCFA concentrations calculated using internal standards. 
ABSORPTION FROM THE RECTUM

Absorption of water and sodium from the rectum was studied by in vivo dialysis, as described previously, ${ }^{11}$ with minor modifications. Briefly, dialysis tubing of $6 \mathrm{~mm}$ diameter was filled with $2 \mathrm{ml}$ of either of the two test solutions and left in the rectum for a period of one hour. The sequence in which these test solutions were used was randomly varied. The solutions used were $140 \mathrm{mmol} / \mathrm{l} \mathrm{NaCl}$ (solution I) or a solution containing $\mathrm{Na} 140$, acetate 60 , propionate 40 , butyrate 20 , and chloride $20 \mathrm{mmol} / \mathrm{l}$ (solution II). The composition of the second solution was designed to reproduce the usual concentrations of SCFAs in normal faeces. ${ }^{6}$ Both solutions had identical molarity $(280 \mathrm{mosm} / \mathrm{kg}$ ). Polyethylene glycol 4000 (PEG 4000, $4 \mathrm{mg} / \mathrm{ml}$ ) was added as a non-absorbable marker. PEG 4000 was assessed turbidimetrically, ${ }^{12}$ sodium and potassium by flame photometry, and chloride in a CCM1 (Chemlab, UK) chloride meter. Net absorption of water and electrolytes was calculated using standard formulas.

In vivo dialysis of the rectum was carried out in nine normal volunteers without gastrointestinal symptoms, and in 17 of 24 subjects with acute watery diarrhoea. Ten of these had $V$ cholerae isolated from the stool. In vivo rectal dialysis reflects epithelial transport if the dialysis bag is in close contact with the rectal mucosa, and does not equilibrate with faeces or fluid. The application of this test to patients without diarrhoea has been validated, ${ }^{1314}$ and the test was discarded in normal volunteers if the contents of the bag were stained by faeces. In patients with diarrhoea, successful studies were possible in only 17 of 24 subjects. The contents of the bag were not faecal stained in any of these. Seven subjects were unable to retain the bag in the rectum for the duration of the test, because of the presence of fluid in the rectum with the urge to evacuate. It was presumed that, in the others, there was no significant fluid in the rectum during the test. The possibility that the contents of the dialysis bag may change if suspended in a solution mimicking diarrhoeal stool water was also examined. Dialysis bags constructed as above, and filled with each of the two test solutions, were suspended for an hour at $37^{\circ} \mathrm{C}$ without stirring in $10 \mathrm{ml}$ of a solution of the following composition (mmol/l): $\mathrm{Na} 135, \mathrm{~K} 15$, $\mathrm{Cl} 100, \mathrm{HCO}_{3} 40$, acetate 10 . This solution is

TABLE I Faecal concentrations and output of individual short chain fatty acids in patients with acute diarrhoea in relation to duration of their illness

\begin{tabular}{|c|c|c|c|c|c|c|c|c|c|}
\hline \multirow[b]{2}{*}{ Day } & \multirow[b]{2}{*}{ No } & \multirow{2}{*}{$\begin{array}{l}\text { Faecal wt } \\
\text { (g) }\end{array}$} & \multirow{2}{*}{$\begin{array}{l}\text { SCFA } \\
\text { output } \\
\text { mmol/24 h }\end{array}$} & \multicolumn{6}{|c|}{ SCFA concentrations mmol/kg } \\
\hline & & & & Total & $C 2$ & $C 3$ & $C 4 i$ & $C 4$ & $C 5$ \\
\hline 1 & 11 & $\begin{array}{c}2346 \\
(364)\end{array}$ & $\begin{array}{l}11 \cdot 4 \\
(3 \cdot 1)\end{array}$ & $\begin{array}{c}9.9 \\
(5.8)\end{array}$ & $\begin{array}{c}3.8 \\
(1.6)\end{array}$ & $\begin{array}{c}4 \cdot 1 \\
(3 \cdot 2)\end{array}$ & $\begin{array}{c}0 \cdot 4 \\
(0 \cdot 3)\end{array}$ & $\begin{array}{c}1.5 \\
(0.8)\end{array}$ & 0 \\
\hline 2 & 22 & $\begin{array}{l}1429 \\
(193)\end{array}$ & $\begin{array}{l}15.2 \\
(2.3)\end{array}$ & $\begin{array}{r}20 \cdot 2 \\
(4 \cdot 9)\end{array}$ & $\begin{array}{l}10.8 \\
(3.0)\end{array}$ & $\begin{array}{c}6.5 \\
(1.9)\end{array}$ & $\begin{array}{c}0.5 \\
(0.1)\end{array}$ & $\begin{array}{l}1.9 \\
(0.7)\end{array}$ & $\begin{array}{c}0 \cdot 3 \\
(0 \cdot 1)\end{array}$ \\
\hline 3 & 24 & $\begin{array}{l}970 \\
(147)\end{array}$ & $\begin{array}{l}22 \cdot 2 \\
(4 \cdot 0)\end{array}$ & $\begin{array}{l}43.1 \\
(10.0)\end{array}$ & $\begin{array}{l}18.5 \\
(4.9)\end{array}$ & $\begin{array}{l}16.0 \\
(3.7)\end{array}$ & $\begin{array}{c}0.7 \\
(0.2)\end{array}$ & $\begin{array}{l}6.8 \\
(1.8)\end{array}$ & $\begin{array}{l}0 \cdot 7 \\
(0 \cdot 3)\end{array}$ \\
\hline 4 & 20 & $\begin{array}{r}866 \\
(202)\end{array}$ & $\begin{array}{c}26.7 \\
(4.9)\end{array}$ & $\begin{array}{l}66 \cdot 5 \\
(12 \cdot 3)\end{array}$ & $\begin{array}{l}25.1 \\
(5.0)\end{array}$ & $\begin{array}{l}23.5 \\
(4.9)\end{array}$ & $\begin{array}{c}1.8 \\
(0.6)\end{array}$ & $\begin{array}{l}14.2 \\
(3.8)\end{array}$ & $\begin{array}{c}1 \cdot 1 \\
(0 \cdot 6)\end{array}$ \\
\hline 5 & 16 & $\begin{array}{l}800 \\
(3211\end{array}$ & $\begin{array}{c}35.4 \\
(7.9)\end{array}$ & $\begin{array}{r}94.8 \\
(16.4)\end{array}$ & $\begin{array}{c}43.4 \\
(9.8)\end{array}$ & $\begin{array}{l}35.3 \\
(7.0)\end{array}$ & $\begin{array}{c}1.4 \\
(0.6)\end{array}$ & $\begin{array}{l}14.2 \\
(3.6)\end{array}$ & $\begin{array}{c}0.5 \\
(0 \cdot 2)\end{array}$ \\
\hline Conv & 6 & $\begin{array}{l}230 \\
(14)\end{array}$ & $\begin{array}{c}28 \cdot 6 \\
(4 \cdot 0)\end{array}$ & $\begin{array}{l}122.9 \\
(11 \cdot 7)\end{array}$ & $\begin{array}{l}50.4 \\
(8.9)\end{array}$ & $\begin{array}{l}37 \cdot 9 \\
(6 \cdot 2)\end{array}$ & $\begin{array}{l}1.4 \\
(0.6)\end{array}$ & $\begin{array}{l}30.0 \\
(8 \cdot 6)\end{array}$ & $\begin{array}{c}3 \cdot 2 \\
(1 \cdot 2)\end{array}$ \\
\hline
\end{tabular}

Values in brackets are SEMs. C2 = acetate, $\mathrm{C} 3=$ propionate, $\mathrm{C} 4 \mathrm{i}=$ isobutyrate, $\mathrm{C} 4=$ butyrate, $\mathrm{C} 5=$ valerate. Conv=convalescent subjects studied two weeks or more after diarrhoea. The differences in valerate. Conv $=$ convalescent subjects studied two weeks or more after diarrhoea. The differences
the mean SCFA output in the first five days are significant $(p<0 \cdot 01)$ by the Kruskal-Wallis test. similar in composition to adult cholera stool. ${ }^{15}$ In tests with solution $\mathrm{I}(\mathrm{NaCl} 140 \mathrm{mmol} / \mathrm{l})$, the PEG concentration changed from $3.88 \mathrm{mg} / \mathrm{ml}$ to 3.80 $\mathrm{mg} / \mathrm{ml}$, and the sodium concentration from 140 to $139 \mathrm{mmol} / \mathrm{l}$ at the end of an hour (mean of three tests). In tests with solution II (SCFA mixture), PEG concentration changed from $4 \cdot 17$ $\mathrm{mg} / \mathrm{ml}$ to $3.94 \mathrm{mg} / \mathrm{ml}$, and sodium concentration from $139 \mathrm{mmol} / \mathrm{l}$ to $142 \mathrm{mmol} / \mathrm{l}$ at the end of an hour. This shows that there is no appreciable difference in dialysis bag content after an hour's suspension in artificial stool water, whether the bag contained sodium chloride alone or the SCFA mixture.

\section{STATISTICS}

All values have been expressed as the mean (SEM). The significance of differences between means was assessed using the Kruskal-Wallis test or the Wilcoxon signed ranks test as appropriate.

\section{Results}

FAECAL CONCENTRATIONS AND OUTPUT OF SCFA IN DIARRHOEA

The concentration and output of SCFA in faeces was low on the first day of illness, but returned towards normal by the fifth day (Table I). Differences between the means of the first five days of illness were significant by the KruskalWallis test $(\mathrm{p}<0.01)$. Patients proved to have $V$ cholerae infection had changes in SCFA concentrations and output similar to patients from whom the organism was not isolated (Figure).

\section{ABSORPTION FROM THE RECTUM}

Table II shows that control subjects had net absorption of water and sodium with solutions I and II. The presence of SCFA in solution II significantly enhanced the absorption of sodium $(p<0.05)$. In patients with acute diarrhoea, solution I was associated with a significant reduction in the absorption of water and sodium ( $\mathrm{p}<0.01$ and $<0.05$ respectively). With solution II, however, the absorption of water improved and sodium absorption returned to values seen in control subjects $(p<0 \cdot 01)$. Net secretion of potassium into the lumen was significantly increased in acute diarrhoea and was unchanged by the presence of luminal SCFA. Net absorption of chloride was seen from solution I, which contained $140 \mathrm{mmol} / \mathrm{l}$ of chloride, but not from solution II, which contained only $20 \mathrm{mmol} / 1$ chloride. Net absorption of chloride from solution I was significantly decreased in patients with acute diarrhoea (Table II). Absorption of water and sodium from the rectum was similar in patients from whom $V$ cholerae was isolated and those in whom this organism was not isolated.

\section{Discussion}

Perfusion of the colon, with a colonoscope in place, has shown impaired absorption of fluid and electrolytes in patients with cholera. ${ }^{+}$This study confirms the presence of this abnormality 
Faecal concentrations and 24 hour output of short chain fatty acids in 15 patients with cultures positive for Vibrio cholerae compared with nine from whom Vibrio cholerae was not isolated.


in patients with acute watery diarrhoea, by a dialysis technique that assessed absorption from the rectum. ${ }^{11314}$ The finding in this study of the abolition of net water absorption from the rectum is compatible with the earlier perfusion study of the whole colon, which showed zero net water absorption in cholera. This study shows that luminal short chain fatty acids overcome this absorptive defect, extending the finding in experimental animals that SCFA can reverse secretion induced by enterotoxins in the colon in vivo. ${ }^{5}$

There is a possibility that rectal dialysis in patients with diarrhoea may reflect exchanges of fluid within the bag with faecal water in the rectum of these patients. For two reasons, however, we feel that such exchanges were not an important confounding factor in our patients. Firstly, in seven of our patients, the dialysis bags were expelled from the rectum along with rectal water; in the others the rectum presumably did not contain more than small amounts of fluid. Secondly, dialysis bags with the two test fluids were suspended for an hour in a solution of composition similar to cholera stool. In these studies, a minor decrease in PEG concentration

TABLE II Net movement of water, sodium, potassium, and chloride in the rectum of control subjects and patients with acute diarrhoea

\begin{tabular}{|c|c|c|c|c|}
\hline & $\begin{array}{l}\text { Water } \\
\mathrm{nl} / \mathrm{cm}^{2} / \min \end{array}$ & Sodium & $\begin{array}{l}\text { Potassium } \\
\mathrm{nmol} / \mathrm{cm}^{2} / \mathrm{min}\end{array}$ & Chloride \\
\hline $\begin{array}{l}\text { Control subjects }(n=9) \\
\text { Solution I } \\
\text { Solution II } \\
\text { Acute diarrhoea }(n=17)\end{array}$ & $\begin{array}{l}+322(63) \\
+348(61)\end{array}$ & $\begin{array}{l}+54 \cdot 5(4 \cdot 9) \\
+73 \cdot 6(6 \cdot 5)\end{array}$ & $\begin{array}{l}-11 \cdot 2(3 \cdot 1) \\
-13 \cdot 8(5 \cdot 8)\end{array}$ & $\begin{array}{r}+179(26) \\
+4(19)\end{array}$ \\
\hline $\begin{array}{l}\text { Solution I } \\
\text { Solution II }\end{array}$ & $\begin{array}{r}-59(81)^{\star} \\
+184(67) \ddagger\end{array}$ & $\begin{array}{l}+26 \cdot 5(11 \cdot 8) \dagger \\
+67 \cdot 3(7 \cdot 8) \ddagger\end{array}$ & $\begin{array}{l}-47 \cdot 9(8 \cdot 3)^{\star} \\
-50 \cdot 0(8 \cdot 3)\end{array}$ & $\begin{array}{r}+110(20) \\
-7(23)\end{array}$ \\
\hline
\end{tabular}

All values given are mean (SEM). A (+) sign indicates net absorption from the lumen, while a $(-)$ sign indicates net secretion into the lumen of the rectum. Solution I contained $140 \mathrm{mmol} / \mathrm{l}$ sodium chloride while solution II contained a mixture of short chain fatty acids. ${ }^{\star} \mathrm{p}<\mathbf{0} \cdot \mathbf{0 1}$ compared with control; $t \mathrm{p}<0.05$ compared with control; $\neq \mathrm{p}<0.01$ compared with solution I, acute diarrhoea. (signifying fluid accumulation in the bag) was noted with both the solutions tested. On the other hand, in the in vivo dialysis studies, a decrease in PEG concentration was noted with solution I, while PEG concentration increased significantly with solution II (signifying net absorption). This suggests that the results obtained indeed reflect epithelial transport.

SCFA can maintain normal fluxes in one direction of sodium and chloride in vitro even after a secretory stimulus, ${ }^{16}$ a finding that has been interpreted to mean that the pathway for electroneutral $\mathrm{NaCl}$ absorption stimulated by SCFA remains unaffected by cyclic AMP. As neutral sodium absorption, however, is not the main absorptive pathway for sodium in the human descending colon, the basis for the present findings remains unclear and an antisecretory effect of SCFA is not excluded. Similar results were noted both in patients with confirmed cholera and in a clinically similar group of patients with acute watery diarrhoea from whom $V$ cholerae was not isolated. Net secretion of potassium into a potassium free solution, also seen in this study, was not reversible by luminal SCFA, and may represent stimulation of active potassium secretion by secondary hyperaldosteronism in these patients. ${ }^{4}$

This study also reports a low faecal output and concentration of SCFA in patients with acute diarrhoea. This is more prominent in the early stages of the diarrhoeal illness, and returns to near normal by the fourth day, by which time the faecal weights are coming down. As luminal SCFA maintain normal colonic absorption in acute diarrhoea, the decrease seen in faecal SCFA output may be of clinical significance. This low faecal output of SCFA seems likely to reflect impaired generation of SCFA ${ }^{17}{ }^{18}$ rather than enhanced absorption of SCFA in the presence of diarrhoea.

Reasons for impaired formation of SCFA could include a decreased dietary intake of unabsorbed carbohydrate, a reduction in bacterial flora due to a 'washout' effect of diarrhoea, and changed conditions for fermentation in the colonic lumen. The oral intake of complex carbohydrates is often restricted in patients with an acute diarrhoeal illness. Starvation reduces colonic luminal SCFA concentrations in experimental animals. ${ }^{19}$ This may be one factor responsible for the low SCFA output reported in these patients with acute diarrhoea. In addition, studies in children and in adults with acute diarrhoea have reported a shift to comparatively more aerobic faecal flora, ${ }^{2021}$ which could influence SCFA growth in the colon.

Studies show that the severity of diarrhoea can be influenced by the salvage of fluid by the colon. ${ }^{22}$ In pigs infected with the transmissible gastroenteritis virus, the occurrence of clinical diarrhoea is related to the capability of the animals for colonic fermentation and SCFA production. ${ }^{23}$ One possibility is that continuing SCFA production can improve fluid absorption in the colon and minimise symptoms. Similarly, the exaggerated response, in starvation, of the rectal mucosa to a secretory stimulus ${ }^{24}$ may be as a result of a lack of luminal SCFA. In addition, a deficiency of short chain fatty acids in the colonic 
lumen can in itself change absorption of fluid. ${ }^{25}$

Efforts at improving oral rehydration solutions have hitherto focused on the role of various substances in improving small bowel absorption. Colonic function is impaired, however, in acute diarrhoeal disease, perhaps in part because of low concentrations of SCFAs. Cereal based oral rehydration solutions are significantly better than the standard glucose oral rehydration solutions in the treatment of diarrhoea. ${ }^{26-28}$ While this is attributed to the presence of oligopeptides and amino acids in the former, their role in the provision of colonic luminal SCFA has not been explored. Similarly, the addition of food to oral rehydration solution further restricts fluid losses and significantly shortens the duration of diarrhoea. ${ }^{29}$ A significant proportion of dietary carbohydrate and starch remains unabsorbed in the small intestine, ${ }^{3031}$ and this may be increased in acute diarrhoea. These provide excellent substrates for the generation of SCFA within the colonic lumen. Attention to enhancing colonic conservation in acute diarrhoea by increasing luminal SCFA may further improve the efficacy of oral rehydration treatment.

The authors thank Mr Rajan Jacob and Mr P Srinivasan for technical help.

This work was sponsored by a grant in aid from the Indian Council of Medical Research, New Delhi, India. The Wellcome Trust Research Laboratory is supported by the Wellcome Trust, United Kingdom, and by the Rockefeller Foundation, USA.

1 Debongnie JC, Phillips SF. Capacity of the human colon to absorb fluid. Gastroenterology 1978; 74: 698-703.

2 Dobbins JW, Binder HJ. Pathophysiology of diarrhea; alterations in fluid and electrolyte transport. Clin Gastroenterol 1981; 10: 605-26.

3 Banwell JG, Pierce NF, Mitra RC, et al. Intestinal fluid and electrolyte transport in human cholera. $\mathcal{F}$ Clin Invest 1970; 49: 183-95.

4 Speelman P, Butler T, Kabir I, Ali A, Banwell J. Colonic dysfunction during cholera infection. Gastroenterology 1986; 91: 1164-70.

5 Ramakrishna BS, Nance SH, Roberts-Thomson IC, Roediger WEW. The effects of enterotoxins and short-chain fatty acids on water and electrolyte fluxes in ileal and colonic loops acids on water and electrolyte fluxes in ileal an
in vivo in the rat. Digestion 1990; 45: 93-101.

6 Cummings $\mathrm{JH}$. Short chain fatty acids in the human colon. Gut 1981; 22: 763-79.

7 Ruppin H, Bar-Meir S, Soergel KH, Wood CM, Schmitt MG. Absorption of short chain fatty acids by the colon. Gastroenterology 1980; 78: 1500-7.

8 Roediger WEW, Moore A. Effect of short chain fatty acids on sodium absorption in isolated human colon pertused through the vascular bed. Dig Dis Sci 1981; 26: 100-6.

9 Binder HJ, Mehta P. Short-chain fatty acids stimulate active sodium and chloride absorption in vitro in the rat distal sodium and chloride absorption in vitro

10 Whitehead JS, Kim YS, Prizont R. A simple quantitative method to determine short chain fatty acid levels in biological fluids. Clin Chim Acta 1976; 72: 315-8.

11 Ramakrishna BS, Mathan VI. Absorption of water and sodium and activity of adenosine triphosphatases in the rectal mucosa in tropical sprue. Gut 1988; 29: 665-8.

12 Hyden S. A turbidimetric method for the determination of higher polyethylene glycols in biological material. Ann $R$ Agric Coll (Sweden) 1956; 22: 139-45.

13 Edmonds CJ. Absorption of sodium and water by human rectum measured by a dialysis method. Gut 1971; 12: rectum

14 Edmonds CJ. Absorption and secretion of fluid and electrolytes by the rectum. Scand $\mathcal{F}$ Gastroenterol 1984; 79 (suppl 93): 79-87.

15 Carpenter CC, Chaudhari RN, Mondal A. A simple effective therapy of cholera. Indian 7 Med Res 1964; 52: 924-32.

16 Binder HJ, Mehta P. Characterization of butyrate-dependent electroneutral $\mathrm{NaCl}$ absorption in rat distal colon. Pflugers Arch 1990; 417: 365-9.

17 Fleming SE, Rodriguez MA. Influence of dietary fiber on fecal excretion of volatile fatty acids by human adults. $\mathcal{F}$ Nutr 1983; 113: 1613-25.

18 Scheppach W, Fabian C, Sachs M, Kasper H. The effect of starch malabsorption on faecal short-chain fatty acid excretion in man. Scand $\mathcal{F}$ Gastroenterol 1988; 23: 755-9.

19 Illman RJ, Topping DL, Trimble RF. Effects of food restriction and starvation-refeeding on volatile fatty acid restriction and starvation-refeeding on volatile fatty
concentrations in the rat. F Nutr 1986; 116: 1694-700.

20 Albert MJ, Bhat P, Rajan D, Maiya PP, Pereira SM, Baker SJ. Faecal flora of South Indian infants and young children in Faecal flora of South Indian infants and young children in
health and with acute gastroenteritis. $\mathcal{F}$ Med Microbiol 1978; 11: $137-43$.

21 Gorbach SL, Banwell JG, Chatterjee BD, Jacobs B, Sack RB. Acute undifferentiated human diarrhea in the tropics. I. Alterations in intestinal microflora. $\mathcal{F}$ Clin Invest 1977; 50: $881-9$

22 Read NW. Diarrhoea: the failure of colonic salvage. Lancet 1982; ii: $481-3$

23 Argenzio RA, Moon HW, Kemeny LJ, Whipp SC. Colonic compensation in transmissible gastroenteritis of swine. Gastroenterology 1984; 86: 1501-9.

24 Levin RJ, Parker AJ. Rectal electrogenic secretion - is it a putative indicator of intestinal secretory status induced a putative indicator of intestinal secretory status induced
by nutritional deprivation in the rat? Exp Physiol 1990; 75: $609-11$.

25 Roediger WE, Rae DA. Trophic effect of short chain fatty acids on mucosal handling of ions by the defunctioned colon. BrF Surg 1982; 69: 23-5.

26 Molla AM, Ahmed SM, Greenough WB III. Rice based oral rehydration solution decreases the stool volume in acute diarrhoea. Bull World Health Organ 1985; 63: 751-6.

27 Molla AM, Molla A, Nath SK, Khatun M. Food based oral rehydration salt solution for acute childhood diarrhoea. Lancet 1989; ii: 429-31.

28 Lebenthal E. Rice as a carbohydrate substrate in ORS. 7 Pediat Gastroenterol Nutr 1990; 11: 293-303.

29 Molla AM, Molla A, Rohde J, Greenough WB 3d. Turning off the diarrhea: the role of food and ORS. $\mathcal{F}$ Pediatr Gastrothe diarrhea: the role of
enterol Nutr 1989; 8: 81-4.

30 Englyst HN, Cummings JH. Digestion of the carbohydrates of banana in the human small intestine. Am 7 Clin Nutr 1986; 44: $42-50$.

31 Cummings JH, Englyst HN. Fermentation in the human large intestine and the available substrates. Am F Clin Nutr 1987; 45: 1243-55. 